C2003 IEEE. Personal use of this material is permitted. However, permission to reprint/republish this material for advertising or promotional purposes or for creating new collective works for resale or redistribution to servers or lists, or to reuse any copyrighted component of this work in other works must be obtained from the IEEE. 


\title{
Dematerialised data and human desire: the Internet and copy culture
}

\author{
Matthew Allen \\ Internet Studies, Curtin University of Technology \\ m.allen@curtin.edu.au
}

\begin{abstract}
Since Licklider in the 1960s [27] influential proponents of networked computing have envisioned electronic information in terms of a relatively small (even singular) number of 'sources', distributed through technologies such as the Internet. Most recently, Levy writes, in Becoming Virtual, that "in cyberspace, since any point is directly accessible from any other point, there is an increasing tendency to replace copies of documents with hypertext links. Ultimately, there will only need to be a single physical exemplar of the text" [13 p.61]. Hypertext implies, in theory, the end of 'the copy', and the multiplication of access points to the original. But, in practice, the Internet abounds with copying, both large and small scale, both as conscious human practice, and also as autonomous computer function. Effective and cheap data storage that encourages computer users to keep anything of use they have downloaded, lest the links they have found, 'break'; while browsers don't 'browse' the Internet - they download copies of everything to client machines. Not surprisingly, there is significant regulation against 'copying' - regulation that constrains our understanding of 'copying' to maintain a legal fiction of the 'original' for the purposes of intellectual property protection. In this paper, I will firstly demonstrate, by a series of examples, how 'copying' is more than just copyright infringement of music and software, but is a defining, multi-faceted feature of Internet behaviour. I will then argue that the Internet produces an interaction between dematerialised, digital data and human subjectivity and desire that fundamentally challenges notions of originality and copy. Walter Benjamin noted about photography: "one can make any number of prints [from a negative]; to ask for the 'authentic' print makes no sense" [4 p.224]. In cyberspace, I conclude, it makes no sense to ask which one is the copy.
\end{abstract}

\section{Introduction}

As the Internet has matured as a technology, and come to play a more 'normal' part in the everyday lives of many people, especially in affluent nations with well-established information infrastructures and traditions that promote distribution and circulation of information (whether that information be political, personal, or commercial), many issues have emerged that mark the difficulties that societies face in adopting, and adapting to, new technological systems. These issues are familiar and include such already-classic cases of dispute and debate as pornography, online gambling, spam, copyright infringement, personal privacy, the security of ecommerce, hate speech and defamation, and so on. I would argue that, in general terms, all of these issues concern two different aspects of our continuing social engagement with information, where 'information' can be understood as an externalised, objectified version of the experiences of being human, and living with other humans. In almost all cases, the moral, political and economic challenges posed by the Internet can be considered as examples of the way we must rethink the value of information (and thus the value of both human experience and accomplishment and its abstraction from the everyday business of being human).

While human experience and endeavour cannot, per se, be replicated, when that experience or endeavour is informationalised, it immediately is capable of being copied. And there are, I would suggest, two very specific and currently high-profile issues about the Internet whose central, defining feature is that they concern 'copying' though in different ways, and with different consequences. The first concern, the one which most readily comes to mind, is generated by the way the Internet provides new and very easy ways for the infringement of the rights of the originator or owner of data to exploit that data for commercial gain. This concern is most publicly visible at the moment in debates around the protection by the entertainment industry of its copyright control of popular music. The second concern, more narrow but no less important to those who are worried about it, is that the Internet readily permits people to find information and pass it off as their own. This concern is widely held within educational and academic communities, expressed as a fear that plagiarism in assignments has increased substantially.

The Internet challenges our dominant understandings of how to value original production, and how to exploit that value; and secondly, it challenges our traditional views of 
the value of being original in the production of information. It does so not because now, suddenly, in the age of the Internet, copyright infringement and plagiarism become possible (for these activities have been taking place for as long as copying has been considered to be 'stealing' or 'cheating'). Rather, the Internet dramatically facilitates the process of taking the value of the original either without paying, or without acknowledgement. What is important is to appreciate the complex mix of reasons why this facilitation occurs. Obviously, a major reason is provided by the technical characteristics of the Internet which harness the very significant capacity of computers to store and manipulate data with the capacity of telecommunications to distribute it globally. I would add that another significant reason is provided by the cultural dynamics of the Internet, as experienced and interpreted by its users, especially as many people who are online have never known of a world 'before' the Internet. This cultural dynamic is not simply that information is 'free' online: rather, I think, the Internet produces a deep cultural belief that information is, legitimately, copyable and redistributable. Copying is more than just copyright infringement of music and software. It is a defining, multifaceted feature of Internet behaviour and culture.

\section{Examples of copy culture}

'Copy culture' can be found on the Internet first of all at the level of technical implementation: David Post identified as early as 1995, in considering the likely development of new forms of copyright law, "“copying' duplicating the information stored in binary files - is an essential step in the transmission of information across the Internet, and thus is required for any and all utilization of works of authorship in this environment." [21]. This technical quality of a packet-switched, computercommunications network is reflected in the common practice amongst Internet service providers (ISPs) of server-side data caching and the, parallel, internal operation of Internet browser software that depends, for normal operation, upon local, client-side caches. Caching of information, whether at the server or the client, is essential to the efficient and effective operation of the Internet [3]. From the perspective of ISPs, caching reflects the economic fundamentals of an interconnected network environment in which the service provider's final profitability depends on the extent to which they can minimise payments to other providers in the total network of networks. The danger, of fragmented networks of interlinked caches rather than a single interconnected network [19 ch.3], is outweighed, increasingly, by the financial advantages that can be gained by service and content providers from the inherently 'cache-able' nature of Internet content.
This situation, as Post predicted, has been recognised repeatedly by lawmakers around the world, as exemplified by the way that caching has been excluded from the strict anti-copying provisions introduced in recent revisions to copyright laws to update them for the Internet age. For example, America's Digital Millennium Copyright Act (2000) implemented "a broad set of safe harbor provisions pertaining to the transmission, storage, and caching of copyrighted information" [23]. The proposed common legislative approach for the European Union permits caching, "the temporary storage on a computer of copies of web pages or other files downloaded from the Internet done to speed up the transmission of data, ... if the caching and browsing has no independent economic significance and is part of an integral and essential part of a technological process." [24]. This position was achieved only after initial constraints on caching had been vigorously opposed by the Internet industry and supporters [20]. In Australia, confusion over whether or not caching (defined as "temporary reproductions of a work that occur 'as part of the technical process of making or receiving a communication' " [27 p.106]. might breach copyright, was resolved by lobbying by librarians and Internet service providers ensured that the exempted caching from being an infringement of copyright in the Copyright Amendment (Digital Agenda) Act 2000 [1, 6]

Therefore, at a fundamental level, copying is inherent to the nature of the Internet. Replication and maintenance of 'copies', on both client and server computers, permit the network to be efficient from a purely technical perspective (minimising data traffic and thus increasing available bandwidth). More importantly, such copying reduces the outlay of resources for both users and service providers (principally time in the first instance and money in the second) making the Internet function more efficiently as a socio-economic system. The extent to which the Internet and copying are interwoven is best exemplified by the complexity with which lawmakers have been confronted in renovating archaic copyright laws: in Australia, for example, computers are now considered to be identical to photocopiers for the purposes of regulated agreements between the Copyright Agency and universities, schools and libraries that require copyright warning notices to be posted where 'copying' might take place.

It is instructive to compare such invisible copying to the more limited, but more visible practice of 'mirror sites' in which an entire website is, with the permission of the original copyright holder, copied elsewhere so as to minimise data-transmission costs. For example, the software distribution website Tucows is mirrored in many locations, principally within the local networks of various Internet service providers, because of the substantial data traffic which would otherwise be directed outside those local networks. The very term 'mirror' implies to users that they are not accessing the original content, but an identical copy for the purposes of saving time and money. Yet, 
essentially, caches also perform as mirrors - the difference is that users, unless they are consciously and actively aware of the process of caching, don't know and are not cued to think that they are not accessing the original. Rather, a cache works precisely because it permits Internet users and service providers to pretend they are accessing originals. The extent and 'invisibility' of this kind of copying generates concerns from some information professionals that caching can mislead Internet users into believing they are accessing original information.

Copying, however, is not just a matter of technology. Browsing the Internet is, metaphorically, a journey (involving navigation or exploration) as best captured in Microsoft's immensely successful 'Where do you want to go today?' marketing campaign for Windows 95. The metaphors of going to information conceal, as does the technical sophistication of caching, the fact that finding information via the Internet involves bringing that information to the user. And, indeed, Internet users are becoming more and more astute in realising that there is no extra time, effort or cost involved in 'saving' what they find online as compared to 'finding' it in the first place. Software such as Web Copier or Web Stripper, or the inbuilt functions within browsers that permit websites to be stored for later use 'offline' makes explicit the technical process which caching utilises invisibly.

Online copy culture is not limited only to the individual practices of web browsing. We see numerous examples of 'copying' in many of the common cultural practices of Internet use. For example, it is common for people to 'copy' emails in a work context: yet the simplicity for the sender in adding recipients to an email message blinds them to the extra work that is involved for recipients in 'dealing' with these copied messages (a point recognised and warned against as early as 1985 [25]). A similar practice can be found amongst those who circulate 'humour' amongst their friends, passing on jokes, pictures, stories to some or all of the contacts stored in their email program, acting rather like a human 'computer virus' (which reminds us that computer viruses, also, work by exploiting the copy and distribute capacity of the Internet).

Yet copying by distribution is not simply individual. It is also structured into many sites that provide information. For example, most major news and current affairs websites provide an 'email a friend this story' option along with each article they publish. While sometimes this option is used, of course, to email the story to an individual, it is also used to distribute information more generally, via electronic mailing lists, which are then often themselves archived, producing multiple copies of the original story on publicly available sites. Since many news-content sites are themselves individual instances of a larger, networked media organisation, multiple copies of these stories will also appear on various websites within the organisation, as for example occurs with zdnet.com, one of the web-based publications of Ziff-Davis Media. This level of public copying online is revealed when searching the Internet in a detailed and methodical manner, as I did when researching an article about Internet Relay Chat (IRC) in 2001 [14]. In just one example, an article by Will Knight, appears through two different zdnet sites (.com and .co.uk) and at cnet.com as well as in the archives of email lists and 'news summary' sites.

Similar, accidental discoveries reveal other kinds of copying While working on e-democracy research, I found that identical, or near-identical summaries of the Accenture report e-Government Leadership: Engaging the Customer, with positive comments about Canada, appeared on numerous websites such as the Insurance-Canada, the European Commission's e-Gateway, MCN Direct Newswire, and Asia-Internet.com (news site); researching another paper, I found identical material on US gambling laws on four 'online gambling' information. Finally, when searching for plagiarism a couple of years ago, I discovered that identical information at Nokia had a habit of turning up on many different websites, not all of them still currently accessible but including 'fan' websites about Nokia mobile phones/m-commerce possibilities; corporate partnerships / distributors; and industry consortia (details on each example given at the end of this paper).

I often encounter this kind of multiplicity online, when checking student work for plagiarism. And, indeed, we can consider it a form of plagiarism - and, to understand copy culture, it is important to understand more about plagiarism. Writing in the mid-1990s, prior to the current horrified fascination with the Internet's capacity to promote plagiarism within educational institutions (for example [17]), Brian Martin noted that substantial, unacknowledged and continuous plagiarism occurs within a variety of bureaucratic institutions, including government, churches, and trade unions, to the extent that it is "such a pervasive and accepted practice that it is seldom considered worthy of concern or mention". Noting that ghost-writing (of, for example, news columns or political speeches) also constitutes plagiarism, Martin argued that two kinds of plagiarism are common in society, so-called "competitive plagiarism" and "institutionalised plagiarism", with widely differing perspectives on their legitimacy. The first is roundly condemned and subject to significant policing and sanction; the latter is quietly accepted and encouraged to serve the aims and interests of the institutions within which it takes place. As Martin explained, in relation to the latter form, "Institutionalized plagiarism is a feature of systems of formal hierarchy, in which credit for intellectual work is more a consequence than a cause of unequal power and position. In bureaucracies, workers are conceived of as cogs in a formal system rather than independent intellectual producers: their work contributes to products of the bureaucracy; putting it in the name of bureaucratic elites is the formal procedure by which this occurs." [15] 
A significant form of institutionalised plagiarism online (though with differently aligned regimes of authority and power) can be found in the code and mark-up from which websites are created. Web designers and developers, whether experienced or novice, amateur or professional, have available to them hundreds, even thousands of collections of code, scripts, templates which can be copied into their own websites. Moreover, even without visiting the many sites which offer collections of resources, web designers soon learn to cut-and-paste source code from their own websites, as well as others, to rapidly speed up the production process.

Though not specifically mentioned by Martin, I would add that the print-news media is also significantly influenced by a form of institutional plagiarism based around the 'press release' in which corporate communications consultants, or public relations managers, those responsible for generating or managing news, produce information in press releases that can, with very little or no alteration be included directly in the work of journalists and media commentators, the people reporting or analysing the news. A recent example came to light in Australia on the television program Mediawatch, concerning the non-attributed copying from press releases (amongst other sources) of commentator Piers Akerman. [18]. This example is not isolated; what makes it unusual is that it was discovered and reported. However, with online searching, it is much easier to discover and analyse plagiarism of information - either from press releases into apparent 'news stories', as regularly occurs online and is, in all likelihood, the origin of the Accenture Report noted above. Moreover, in the online environment, cutting and pasting of information from one website to others, from one web-distributed document to others, is much easier.

And of course, as well as this institutional form, competitive plagiarism abounds in the transfer of Internet content into (predominantly) student assignments. Malaysia's Star Online reported one former university student saying "Back when I was a student, I used the Internet regularly as a source of information. It was so much easier to search for information online compared to going through books in the university library. But then, the temptation to simply cut-and-paste a whole article was there, and you could say that without putting up much of a fight, I gave in. All I needed was a search engine, like Yahoo!. Once I found a suitable article, I'd simply make a few changes and I'm done." [9]

The Star also reported that, in a survey of 95 students at a college in Malaysia " $39 \%$ of the respondents said they were of the view that copying is acceptable as long as the whole work is not copied in its entirety. Another $28 \%$ believe that lifting a sentence or two from various sources is acceptable." [9]. The readiness of students to cheat, in some form or another, is demonstrated by a recent Australia survey of students at Monash University: "Almost 80 per cent of undergraduate students confessed anonymously to at least one of 18 different forms of cheating" [28]. However the Internet, while not changing this willingness - as noted in the article cited, similar results were obtained in the 1960s - makes responses more difficult. As various authors have noted, not only does the Internet make information much more readily available, it does so in a cultural context which disinhibits students from copying. The information is already there in electronic form (as opposed to having to be rewritten or typed from a printed source).

More importantly, information is presented in ways that subtly suggests copying is appropriate, precisely because, online, many forms of copying are both encountered and encouraged. The difficulty for students is in distinguishing between the different requirements of academic work and the enticing practices of being online.

\section{Understanding copy culture and the Internet}

The array of examples just given shows how the Internet is, through its technologies and the cultural practices that give them life, dominated by a 'copy culture' that is more than just specific cases of copyright infringement and plagiarism and is, instead, a deeper, foundational aspect of the socio-technological system that is the Internet. Indeed, 'cut and paste' is more than just a skill learned at an early age by every computer user; or a technique of website creation. It is, as Manovich suggests, a central component of the cultural codes by which the experience of digital workers in the contemporary world are made meaningful [16]. To be digital in today's world is, always, to have available, without thinking, the 'cutand-paste' possibilities of computing, applied to data that might come from anywhere within the network. Indeed one blogger, 'caught' plagiarising from an online news site, explained his actions by saying that "some of his material was 'copied and pasted' and some was not" [8].

In this section of my paper, I will explore, in more detail, how the value of information might be combined with the way we assign value to information activity, to understand the particular significance of this culture of copying. In doing so, I will show how copying reflects the particular convergence of computing and telecommunications that is the Internet

Returning for a moment to plagiarism, one American academic believes that "We are raising a generation of students who think anything that's on the Internet is free" [22], also [7]. And, indeed, on the Internet uses can find many freely available goods and services - freeware applications, email services, articles, books, and more provided in one of two ways. Firstly, we encounter 'free' content as a form of marketing (in which the content, eventually, will lead to some paid-for activity) or as part of the attention economy in which free content is provided in 
return for 'attention' to advertisements that then produces revenue for the provider [10]. Secondly, despite commercialisation (or indeed because of it) users continue to find on the Internet genuinely 'free' goods that are part of a gift economy [12], based on the fact that "the digitisation of information and product massively reduces the costs of distribution; the global connectivity of the net increases the size of the potential market to the point where returns [in the form of prestige] can outweigh [real] costs" $[14, \mathrm{p} .52]$

Yet the meaning of copy culture can be reduced to it being solely a response to the significant quantities of material that one can have 'for nothing': this implies that Internet users are always taking, rather than exchanging. Rather, the workings of the attention and gift economies demonstrate how value online operates through both replication and distribution. The Internet, by being an interaction between computing and telecommunications, unifies two distinct aspects of the social and economic uses to which information is put. Each instance of reproduced and distributed data functions as an original - as for example when my browser loads cached information as if it has come from the originating website, or as the music which has been acquired instead of the paid-for data available on disc (or, now, increasingly online but in protected form). Thus a discourse of online value emerges that implies, for users, that value is gained in the acts of reception and distribution rather than in the data itself.

Hence, while some have argued, for many years and with little impact that "information wants to be free" [5] and, more recently, cynical commentators have suggested that "information wants to get paid" [11] I would conclude, from the examples given above, that the culture of copying online suggests that we now must ask if now if "it is true that information wants to replicate?" [2] And, for media activists, whether corporate or not, who are seeking the widest possible audience for their message, information does want to replicate. What concerns copyright owners and concerned academics is that certain kinds of replication are invalid, because the value of the information to them lies in the maintenance of a proper relationship between original and copy: indeed, academics make a very proper living from the controlled utilisation of 'copies' (as in this paper) in which the validity of the copy stems from its identification in relation to the original. Similarly, the music industry, beset by alleged crises stemming from the trading of $\mathrm{mp} 3$ files, wants to maintain - through technological controls - a more accountable relationship between a bought original and a subsequent copy.

These concerns are, for the most part, a response to the changing nature of people's understandings of the value of data when it is dematerialised and digital. Internet users are, more and more, encountering instances of 'alreadycopied' information and thus do not readily distinguish between originals and copies. For them, the information is cast free from a temporal narrative of origination and reproduction, into a syntactic web of equivalent, identical instances of information which are, effectively, multiple originals. The worth of information is determined, now, as much by the extent of and the acts of its distribution as its inherent worth (whether for the originator or, in the case of plagiarism, for the copyist falsely claiming origination). Action against copying - as is sometimes necessary, both for commercial and intellectual reasons - seek to control value through a strict relationship of original to copy, not so much by preventing copying completely, but by permitting only in situations where the 'copy' is clearly identified as such.

Walter Benjamin, writing in the 1920 s, noted in relation to photography that "one can make any number of prints [from a negative]; to ask for the 'authentic' print makes no sense" [4, p.224]. In cyberspace, in contrast, it makes no sense to ask which one is the copy, since all instances of digitised, dematerialised data function as if they were originals. The document I download from a website to my desktop is there, precisely, so that it can be an original - so I do not have to spend time revisiting and re-downloading the same data. In this copy culture of the Internet, laws and conventions against copying work by maintaining the fiction of the 'original' when, in the digital world, copies have been replaced in many cases by multiple originals.

\section{Desiring network efficiency}

Pierre Levy argued that "in cyberspace, since any point is directly accessible from any other point, there is an increasing tendency to replace copies of documents with hypertext links. Ultimately, there will only need to be a single physical exemplar of the text" [13, p.61]. This vision is impractical and unlikely, even if theoretically possible; more dangerously, it also blinds us to the fact that linking is not a replacement for possession of an original (whether in physical or electronic form) and that possession, however fleeting, remains a necessary element in the way that information is valued in the age of the Internet. Levy is, essentially, arguing that, to the extent information can satisfy or enact our desires, it is access to that information which matters most, privileging that element of the Internet most concerned with telecommunication rather than the power of the computers themselves to multiply, and store data. But there is more to the Internet than simply accessing information - indeed links have, themselves, become 'data' and are even more heavily copied than other forms of online content. As I will conclude, the desiring Internet user, beneath the surface of accessing information, is searching for more than just another website: they desire to participate in the 'network'

By desire, I mean that sense of wanting to complete a loss, a longing for something beyond the self that can only be gained tentatively and temporarily in acts which imply 
fulfilment but replenish the underlying sense of emptiness described by Lacan, for example, as the 'gap' between the image of the self, and the self experienced, This sense of loss is, in large measure, generated by the relationships of power and powerlessness within which human subjectivity is formed. And, online, power comes not principally from 'access', but from participation in the network, with its inherent emphasis on copying and distributing data. Within this frame of analysis, the 'email a friend this story' can be read, much more as 'email this story because you desire to enact friendship'.

The Internet's success, becoming the single dominant networked information and communication technology, distributed both globally and locally, owes much to the interaction of the technological adaptability of its underlying protocols which, by design, allow interconnection of diverse and distinctive computing devices; and which treat the information which flows between these devices as generic 'data'. The Internet is not just a network: it is also the idea of interconnectedness and it is this idea which is mobilised by the twin processes of copying and replicating which are commonly found online.

Desire is also expressed in copy culture through the fact that digital data is so efficiently copied, stored, retransmitted and, inherent to the Internet is this idea of efficiency. Thus, to return to my argument that copy culture produces different kinds of understanding of value, we can see that the value for an individual of having 'originals' that others might think of as copies is in enacting, at a local level, the efficiency which underpins the network itself. The desired subject position within Internet culture is, therefore, to take up, consciously, the kinds of technological forms of copying and distributing and, effectively, become part of the network oneself.

\section{Conclusion}

In conclusion, we can see that understanding the Internet's copy culture helps to show why this technological form presents a challenge for users and regulators in relation to specific issues of copyright and plagiarism (both allowed and prohibited). Yet there is nothing inherently causal about the Internet in this regard: people do not download music just because it is online; nor do they plagiarise for that reason. Rather to describe the Internet as being dominated by copy culture sheds some light on the deeper structures of meaning through which we can understand the Internet's role as a prime location for the increasingly common experience of virtual subjectivity. And, amidst an array of technological efficiency and dematerialised data, the subject of virtuality desires some sense of efficient connection, mediating themselves through a plethora of 'copying'.

\section{References}

[1] ALIA (Australian Library and Information Association). Copyright Amendment (Digital Agenda) Act 2000 website. 2001. Available at: http://www.alia.org.au/copyright/digital.agenda/

[2] Allen, Matthew, "The Copy: Theorising the Internet through Virtuality”, Keynote paper, Digital Publics: A Debate. Fibre culture Conference, Melbourne, Australia December 2001, available at: http://www.curtin.edu.au/home/allen/papers/

[3] Athanasekou, P. Eve. "Internet and Copyright: An Introduction to Caching, Linking and Framing", The Journal of Information, Law and Technology, n.2. 1998, Available at: http://elj.warwick.ac.uk/jilt/wip/98_2atha/default.htm

[4] Benjamin, Walter [ed. Hannah Arendt], Illuminations, Schocken Books, New York, 1969.

[5] Clarke, Roger, "Information Wants to be Free", 2001, available at:

http://www.anu.edu.au/people/Roger.Clarke/II/IWtbF.html

[6] Catanzariti, Therese, "Copyright digital reforms: the Copyright (Digital Agenda) Bill”, Internet Law Bulletin, 2.2, Mar-Apr 1999, pp.28-31.

[7] Clayton, Mark, "Term Papers At the Click Of a Mouse" Christian Science Monitor, 1997, available at: http://csmweb2.emcweb.com/durable/1997/10/27/feat/learning.1. html

[8] Forbes, Daniel, "Noted War Blogger Cops to Copying", Wired News, April 7, 2003, available at:

http://www.wired.com/news/conflict/0,2100,58346,00.html

[9] Fredericks, Michael A, "Cheating, the copy-and-paste way", Star Online, 2002, available at:

http://202.186.86.35/special/online/plagiarism/mike_cutpaste.htm 1

[10] Goldhaber, Michael, "The Attention Economy and the Net", First Monday, 2.4, 1997, available at:

http://www.firstmonday.dk/issues/issue2_4/goldhaber/

[11] Hotwired, Information wants to Get Paid (headline), 25 February 1997, available at:

http://hotwired.wired.com/frontdoor/97/08/index1a.html

[12] Kollock, Peter. "The Economies of Online Cooperation: Gifts and public goods in cyberspace", in Marc A. Smith and Peter Kollock (eds), Communities in Cyberspace, Routledge, London, 1999, pp.220-239.

[13] Levy, Pierre [trans. Robert Bononno]. Becoming Virtual: Reality in the digital age, Plenum Trade, New York, 1998.

[14] Long, Jane and Matthew Allen. "Hacking the undernet: libertarian limits; commercial containment", Australian Journal of Communication. 29.3, 2001, pp.37-54 available (in draft form) at: http://www.curtin.edu.au/home/allen/papers 
[15] Martin, Brian, "Plagiarism: a misplaced emphasis", Journal of Information Ethics, 3.2, Fall 1994, pp. 36-47, available at: http://www.uow.edu.au/arts/sts/bmartin/pubs/94jie.html

[16] Manovich, Lev, The Interface as a New Aeshetic Category, Through the Looking Glass [digital exhibition], 2001, available at: http://www.voyd.com/ttlg/textual/manovichtext.htm

[17] Mayfield, Kendra, "Cheating's Never Been Easier", Wired News Sept. 4, 2001, available at:

http://www.wired.com/news/school/0,1383,45803,00.html

[18] Mediawatch. "Piers' Plagiarism", ABC TV 10/2/2003, reported at:

http://www.abc.net.au/mediawatch/transcripts/s780381.htm

[19] National Research Council: Committee on the Internet in the Evolving Information Infrastructure, The Internet's coming of age. National Academy Press, Washington DC, 2001, available at: http://www.nap.edu/html/coming_of_age/

[20] Nuttall, Chris, "Opposition grows to web caching ban", $B B C$ News, 1999, available at:

http://news.bbc.co.uk/1/hi/sci/tech/298498.stm

[21] Post, David, "Copyright Law on the Internet: The Special Problem of Caching and Copyright Protection" Draft paper, published via the Cyberspace Law Institute, 1995, available at: http://www.cli.org/Caching.html

[22] Renard, Lisa. "Cut and Paste 101: Plagiarism and the Net", Educational Leadership 57.4, 1999, available at:

http://www.ascd.org/articles/9912el_renard.html

[23] Samuelson, Pamela. "Toward a 'new deal' for copyright in the information age, Michigan Law Review, 100.6, May 2002, pp. 1488-1505.

[24] Schollenberger, David [Partner, DK Freeman London]. Entertainment without Borders, 2003, available at: http://www.arentfox.com/quickGuide/businessLines/intlprop/intel propRelatedArticles/ra2003-03-11klein/ra2003-03-11klein.html

[25] Shapiro Norman Z.and Anderson, Robert H., Toward an Ethics and Etiquette for Electronic Mail, RAND Corporation 1985, available at: http://www.rand.org/publications/MR/R3283/

[26] Standing Committee on Legal and Constitutional Affairs, House of Representatives, Parliament of Australia, Advisory Report on the Copyright Amendment (Digital Agenda) Bill 1999, AGPS, Canberra, 1999, available at:

http://www.aph.gov.au/house/committee/laca/digitalagenda/conte nts.htm

[27] Stefik, Mark, (ed.), Internet Dreams: Archetypes, Myths, and Metahors, MIT Press, Cambridge, MA, 1996.

[28] Szego, Julie. Shock finding on uni cheating, The Age, January 7, 2003, available at:

http://www.theage.com.au/articles/2003/01/06/1041566360939.ht $\mathrm{ml}$

\section{Details of examples referred to above}

\subsection{Example 1: Accenture report}

"According to the study, Canada's eGovernment initiative is differentiated by its customer-service vision; methods for measuring success of services; broad, integrated approach to offering government services through multiple service-delivery channels; and a crossagency approach to online services. Further, the government has placed its citizens and businesses at the core of its eGovernment initiative, identifying services for individual customer segments, and government executives view eGovernment as an evolutionary process that is part of a broader service transformation effort."

Found at:

http://www.insurance-

canada.ca/market/canada/AccentureEG200304.php;

http://www.e-

gateway.net/infoarea/news/news.cfm?nid=2967;

http://195.112.22.43/mendirect/issues/mendirect140403.as $\mathrm{p}$; and http://asia.internet.com/asia-

news/article/0,3916,161_2178511,00.html

\subsection{Example 2: Gambling information}

"Up until the last few years, the regulation of gambling had been relegated to state legislatures. Predictably, states have varied in their degree of regulation. Utah, a universally renowned conservative state, does not permit its citizens to participate in any form of gambling. On the other hand, Nevada openly declares in their statutory law that gambling is "vitally important to the economy of the state and the general welfare of the inhabitants." All states have legalized at least one form of gambling (usually a lottery)."

Found at:

http://www.online-horse-racing.net/legal-gambling.html; http://www.worldonlinegambling.com/laws/onlinegamblin glegal.htm; http://www.free-online-casino-tips.com/ laws/onlinegamblinglaws.htm; and http://www.geocities.com/mehamm0/netgambling.htm

\subsection{Example 3: Nokia corporate information}

"Nokia Internet Communications, with headquarters in Mountain View, Calif., provides world-class Network Security, Virtual Private Network and Wireless Software solutions that assure the security and reliability of corporate enterprise and managed service provider networks. Nokia is committed to enhancing the end user experience by enabling personal, trusted transactions for the Mobile Information Society."

Found at: 
http://www.hp.com/hpinfo/newsroom/press/12dec00b.h tm

http://www.businessobjects.com/news/press/press2000/ wireless_bi.htm

http://www.npawest.com/vendors.html

http://www.broadwing.com/prodserv/midlarge/midlarge_s ervices/midlarge_services_bts/midlarge_services_bts_part nerships/midlarge_services_bts_partnerships_nokia.htm 